\title{
SIS therapy in the treatment of distal radius epiphyseal fracture (Case report)
}

\author{
JIMBU Diana ${ }^{1,2}$, OPREA Doinița ${ }^{1,2}$, SARIKAYA Emre ${ }^{1,3}$, ILIESCU Mădălina \\ Gabriela $^{1,2}$, IONESCU Elena Valentina ${ }^{1,2}$, BORDEI Petru ${ }^{1}$, ENACHE Florin Daniel ${ }^{1,3}$, \\ IONESCU Constantin ${ }^{1,3}$, BULBUC Ionut ${ }^{1,3}$, OBADĂ Bogdan ${ }^{1,3}$
}

Editor: Constantin Munteanu, Romanian Association of Balneology, office@bioclima.ro Reviewers: Dogaru Gabriela and Rotariu Mariana

*Corresponding authors: Oprea Doinita, E-mail: doi opr@yahoo.com

${ }^{1}$ Faculty of Medicine, „Ovidius” University of Constanta, Romania

${ }^{2}$ Department of Rehabilitation, Balneal and Rehabilitation Sanatorium of Techirghiol, Constanta, Romania

${ }^{3}$ St. Andrew Emergency County Clinical Hospital of Constanta, Romania

\begin{abstract}
Introduction. Fractures of the distal radius epiphysis are the most common fractures of the upper limb, present both in the general population active following major trauma and in the elderly population in minimal trauma due to osteoporosis. Among the adjuvant therapies for orthopedic treatment of distal radius epiphyseal fracture we can list Super Inductive System (SIS), a therapy based on the interaction between the electric field and the human body with the improvement of the healing process by acting on the pathophysiological stages of bone callus.

Material and method. A clinical case study was performed on a 28-year-old patient, hospitalized and treated in the neurosurgery department of the Constanta County and Emergency Hospital for a polytrauma by road accident (passenger) with amyelotic cervical vertebral trauma, thoracic trauma and trauma to the right upper limb, subsequently performing 12 SIS therapy sessions at the Balneal and Rehabilitation Sanatorium of Techirghiol. CT examination of the cervical spine reveals fractures of C4 vertebra (the blade and pedicle) and C5 vertebra (vertebral body, lamina and pedicle). Right forearm radiography reveals fracture of the right radial styloid. After conservative treatment of the cervical injury and orthopedic treatment of the upper limb injury, the clinical evolution is favorable, allowing the patient to be discharged and allowed to do 12 sessions of SIS therapy, 3 times a week, within 4 weeks. The subsequent clinical and paraclinical evolution was favorable for the outpatient orthopedic ambulatory reevaluation performed at 5 weeks.

Results and discussions. Due to the type of fracture of the radial distal epiphysis (linear fracture without displacement), absence of comorbidities and young age, led to the indication of orthopedic treatment with immobilization in the antebrachio-palmarcast, which allowed subsequent physiotherapy.
\end{abstract}

Keywords: radial fracture, callus, polytrauma, cervical spine, lamina, Super Inductive System,

\section{INTRODUCTION}

The radius is a long, paired bone located on the side of the forearm, on the side of the ulna and on the thumb. It has a body and two epiphyses. The distal or inferior epiphysis is much larger (1-3). The fracture of the distal extremity of the radius is one of the most common fractures of the upper limb. Among the most important causes of fracture can be listed the important traumas, if we talk about the general active population or the minimal traumas due to osteoporosis if we talk about the elderly population (4). According to the Frykman classification, there are eight types of fractures, the first two being extraarticular and the rest intraarticular (5). Clinical examination of the patient with fracture of the distal radius epiphysis reveals: localized edema, bruising, deformity at the fracture site and sensitivity to palpation $(4,5)$.

Among the treatment methods of the distal radius epiphyseal fracture we can list the orthopedic treatment, whose effectiveness can be improved by the Super Inductive System (SIS) (6). SIS therapy is based on the interaction of high intensity electric field and human body that produce the following changes: intensification of blood circulation in the affected area, facilitating the formation of fibrocartilaginous callus, initiating the process of progressive cartilage mineralization and promoting bone remodeling (6-10).

The objective of this case presentation is to demonstrate the effectiveness of physiotherapy treatment with Super Inductive System in the fracture of the distal radius epiphysis, with a new evidence of effectiveness of rehabilitation treatments on musculo-scheletal patologies $(11,12)$.

Material and method. We present the case of a 28 -yearold patient, without significant personal pathological history, who is hospitalized in the neurosurgery department of the Constanta County Emergency Hospital for a polytrauma due to a road accident (passenger) with amielic cervical trauma, thoracic trauma and right upper limb trauma. Clinically at hospitalization the patient is conscious, cooperative, 
Material and method. We present the case of a 28year-old patient, without significant personal pathological history, who is hospitalized in the neurosurgery department of the Constanta County Emergency Hospital for a polytrauma due to a road accident (passenger) with amielic cervical trauma, thoracic trauma and right upper limb trauma. Clinically at hospitalization the patient is conscious, cooperative, Glasgow Scale GCS $=15$, with no signs of meningeal irritation, no cranial nerve deficiencies, no motor deficits (upper right limb difficult to examine in the context of functional impotence and edema due to fracture of the distal radius), without sensitivity disorders, ROT present symmetrically bilateral, RCP in flexion, bilateral with neck pain and pain in the right upper limb (distal extremity).

Examination of the native craniocerebral computed tomograph does not reveal post-traumatic intracranial lesions. The cervical spine CT scan shows fracture lines without displacement of the lamina and the right pedicle at the level of the $\mathrm{C} 4$ vertebra (fig. 1,2) and the vertebral body, the lamina and the right pedicle of the C5 vertebra (fig. 1, 2). without changes in the axis of the cervical spine. Radiography of the right anterbrate shows a fracture without displacement of the right radial styloid. The patient is hemodynamically and cardio-respiratory stable on presentation, with $\mathrm{BP}=130 / 70 \mathrm{mmHg}$, $\mathrm{AV}=70 \mathrm{bpm}$ and $\mathrm{SpO} 2=100 \%$
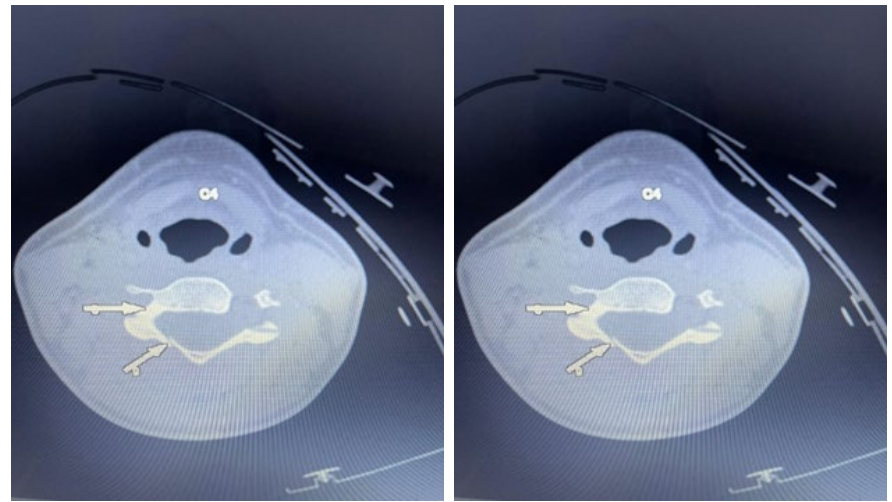

Fig 1. Tomographic image of the cervical spine, centered on the $C 5$ vertebra and the C4 vertebra

Immobilization in Philadelphia collar and orthopedic treatment with immobilization in the right antebrachio-palmar cast is performed with radiographic control before (fig. 3.A, 3.B) and after reduction (fig. 4.A, 4.B).

The favorable clinical evolution after a week of rest and antialgic, anti-inflammatory and anticoagulant treatment allows the patient to be discharged and to start the therapy with Super Inductive System at the Balneal and Rehabilitation Sanatorium of Techirghiol. There are 12 SIS therapy sessions divided into 3 sessions per week, within 4 weeks, using the A-1014 program. After the last SIS session, a right forearm control radiograph is performed, which shows a very good paraclinical evolution with the total callus of the fracture line of the distal epiphysis of the radius (fig. 5.A, 5.B).

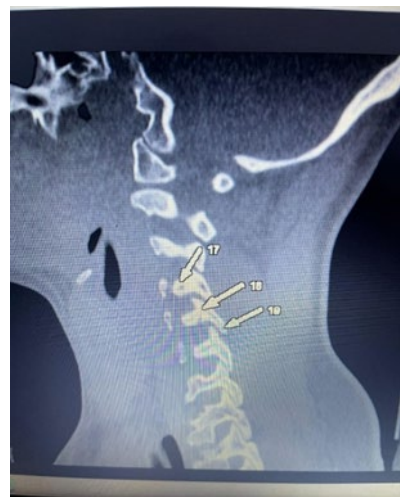

Fig 2. Tomographic image of the cervical spine, highlighting the fracture lines of the $C 4$ and $C 5$ vertebrae.
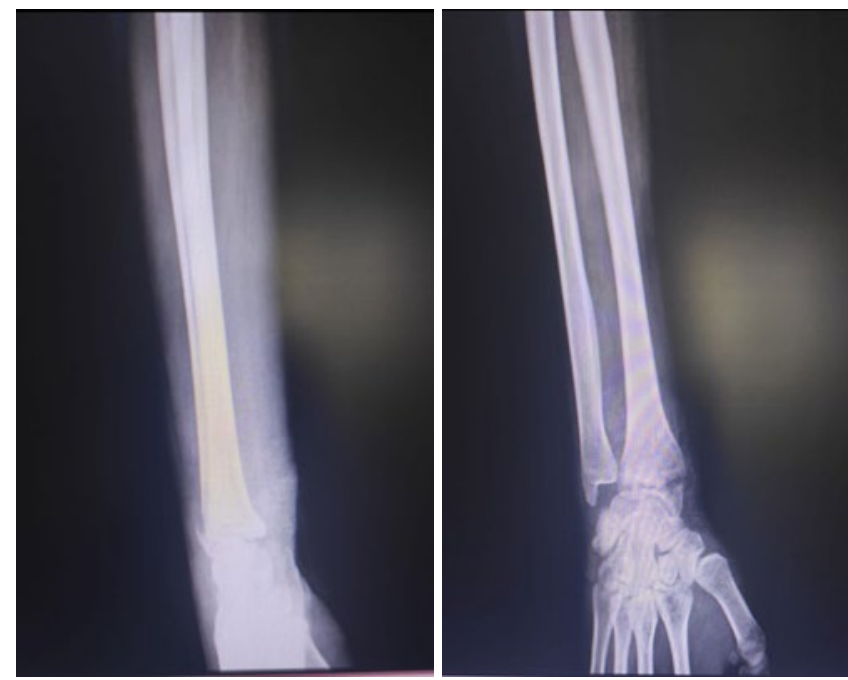

Fig 3-X-ray of the left forearm, before the orthopedic reduction of the fracture of the distal epiphysis of the radius, the lateral incidence (A) and antero-posterior (B).

Results and discussions. The causes of fractures of the distal radius epiphysis are represented by severe traumas, including in the context of polytraumas in the active population or by minimal traumas in the elderly population in the context of osteoporotic pathology (4). Distal radius epiphyseal fractures represent approximately $12 \%$ of total upper limb fractures, being the most common types of fractures in this segment (5). 
The treatment of fractures of the distal radius epiphysis can be surgical or orthopedic, considering the type of fracture (linear or comminutive, with or without displacement), the associated injuries (in the context of polytraumas) and the patient's comorbidities $(5,9)$. Adjuvant physiotherapy treatment is performed after treating acute lesions and clinical and biological stabilization of the patient, but preferably as early as posttraumatic, to increase the effectiveness of treatment $(4,6)$. Physiotherapy in radius fractures may consist of therapy with SIS (Super Inductive System - fig. 6), which is a treatment divided into 3 weekly sessions, up to a total of 15 sessions. The center of the applicator is positioned above the affected area at a minimum tissue distance. The recommended intensity during the operation is above the sensitivity threshold, up to the motor threshold. (10).

The evolution is followed clinically and imagistically, performing a forearm radiograph at the end of the physiotherapy sessions. The presence of the cast is not a contraindication to the use of SIS therapy, its effectiveness not being affected (10).
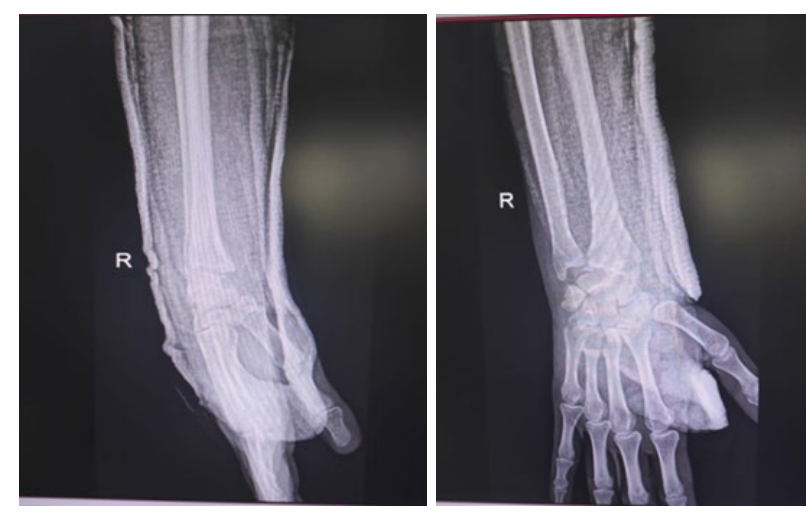

Fig 4- Left forearm radiograph, after orthopedic reduction of the distal radius epiphysis fracture, lateral incidence (A) and antero-posterior incidence $(B)$.
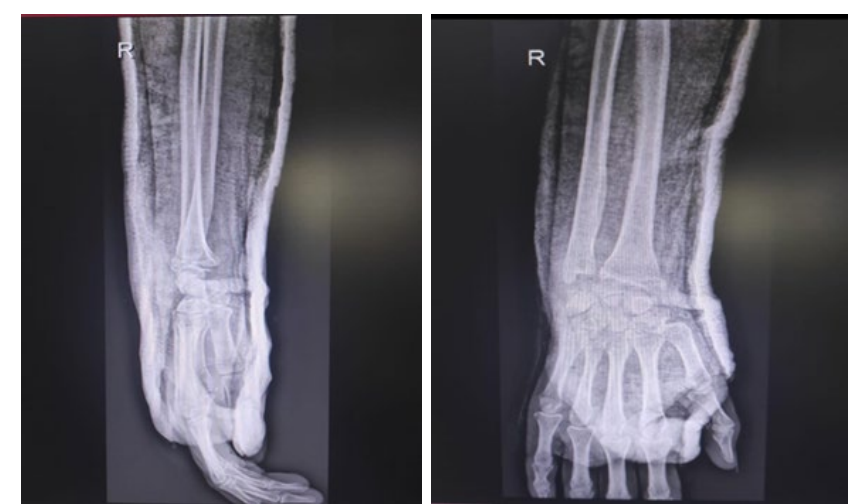

Fig 5-X-ray of the left forearm, at 5 weeks, lateral incidence (A) and antero-posterior incidence (B).

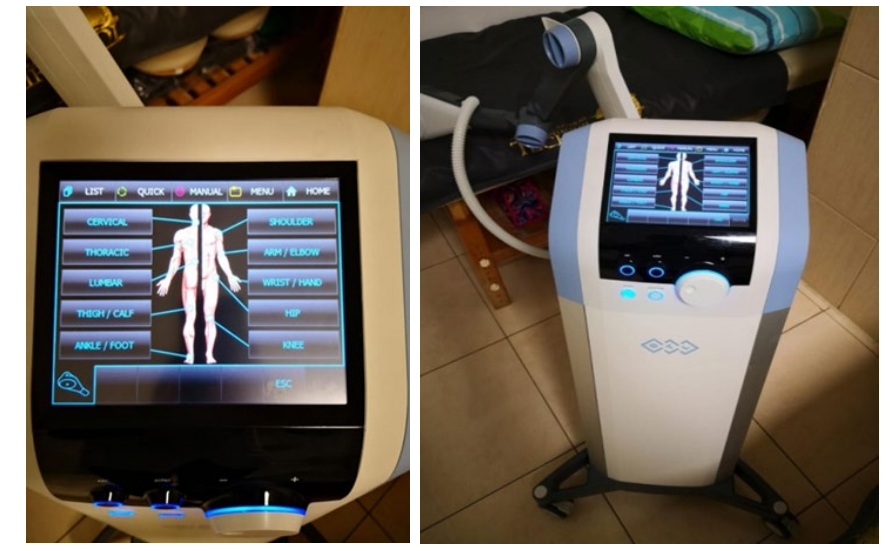

Fig 6- Super Inductive System (personal archive)

\section{Conclusions}

The mechanism of fracture of the distal epiphysis of the radius was by the hyperextension of the hand on the forearm, by supporting it on the car board, at the moment of impact. The type of fracture of the radial epiphysis (linear fracture without displacement), the absence of comorbidities, the young age and the indication of orthopedic treatment with immobilization in the antebrachio-palmar cast, made possible the subsequent physiotherapy. A favorable factor in the patient's evolution was the absence of post-traumatic mielic lesions, secondary to $\mathrm{C} 4$ and $\mathrm{C} 5$ fractures, with the absence of neurological deficits at hospitalization (Frankel "E" score), which allowed shortening the hospitalization period and early recovery by SIS therapy. The young age and the patient's compliance at the treatment (avoiding traumas, maintaining the prone position of the forearm and maintaining the integrity and functionality of thecast) led to a good imaging evolution with complete callus to the control radiograph at 5 weeks. The clinical evolution was favorably influenced by the symptomatic treatment, by the therapy with Super Inductive System and by the methods of reducing the edema (prone position and ice applications), by remitting the pain symptoms produced by the post-traumatic edema. Electrotherapy using new inovative methods such high intensity electromagnetic field, and other methods (13-16) can contribute in future development of the rehabilitation programs for many pathologies. 
Author contributions regarding this study:

All authors (JD, OD, SE, IMG, IEV, BP, EFD, IC, BI, $O B)$ had equal contribution.

\section{Ethics approval and consent to participate:}

The approval of the local ethics comittee (Ethics Committee for Scientific Research of the St. Andrew Emergency County Clinical Hospital of Constanta), (approval no 348/25.05.2021) was obtained prior to write the study. Informed concent from the patient was obtained.

Acknowledgements: The autors thank to the patient who took part in this study.

\section{Funding:}

No funding was received.

\section{Conflict of Interest:}

The authors declared no conflicting interest.

\section{References}

1. Bordei Petru. Ulmeanu Dan. "Descriptive anatomy of the upper limb". Ex Ponto. Constanța 1996, 18-30; 137-140.

2. Bordei Petru. Ulmeanu Dan. "Arthrology." Ovidius University Press. Constanta 2001, 89; 94.

3. Victor Papilian. "Human Anatomy of the Locomotor System - Edition completely revised by Dr. Ion Albii". 11th edition. Editura Bic All. Timisoara 2003, 62-66.

4. Randall L. Braddom. "Physical and rehabilitation medicine". 4th Edition. Bucharest 2015, 3; 886-889.

5. Dinu M. Antonescu. "Pathology of the musculoskeletal system". Medical Publishing. Bucharest 2006, 915.

6. Cristina Daia. "Electrotherapy - Practical principles". University Publishing House. Bucharest 2019, 24.

7. Viorel Lucescu. "Degenerative diseases of the spine Clinic, diagnosis and recovery treatment. Course notes." Dobrogea Publishing House. Constanta 2009, 57-75.

8. Viorel Lucescu. "The contribution of balneophysiotherapy in the suffering of the spine". Journal of
Balneophysiotherapy and Medical Recovery. Bucharest 1996, no.1-2, 113-118.

9. Liviu Pop. "Joint clinical and muscular evaluation". "Iuliu Hațieganu" University Medical Publishing House. Cluj 2002, 67-71.

10. BTL-6000 Super Inductive System Elite, BTL Therapeutic Enciclopedya, 2018.

11. Popa F.L, Iliescu M.G., Stanciu M., Georgeanu V.Rehabilitation in a case of severe osteoporosis with prevalent fractures in a patient known with multiple sclerosis and prolonged glucocorticoid therapy. Balneo and PRM Research Journal 2021, 451, 12 (3): 284-288.

12. Iliescu D.M., Bordei P., Ionescu E.V., Albina S., Oprea C., Obada B., Lupu A.A., Hangan T.L., Iliescu M.G. Anatomic- imaging Correlations of Lumbar Diskvertebral Morphometric Indices. Int J Morphol, 2017; 35 (4), 1553.

13. Ober C., Pestean C., Bel L., Taulescu M., Milgram J., Todor A., Ungur R., Leșu M., Oana L. Use of clinical and computed tomography findings to assess long-term unsatisfactory outcome after femoral head and neck ostectomy in four large breed dogs. Acta Vet Scand. 2018 May 10;60(1):28.

14. Ungur R.A., Florea A., Tăbăran A.F., Scurtu I.C., Onac I., Borda I.M., Irsay L., Ciortea V.M., Dronca E., Zdrenghea M.T., Suciu Ş.M. Chondroprotective effects of pulsed shortwave therapy in rabbits with experimental osteoarthritis. Rom J Morphol Embryol. 2017;58(2):465472.

15. Ungur R., Dronca M., Crăciun E.C., Rusu R.L., Văleanu M., Onac I., Borda I.M., Irsay L. Improvement of total antioxidant status, a possible bioeffect of the ultrasound therapy - A pilot study. Rev. Romana Med. Lab,2011; 19: 177-183.

16. Onac I., Singureanu V., Moldovan G., Ungur R. High Frequency Pulsatile Electromagnetic Fields and Ultrasound Pulsatile Fields Impact on Germination Dynamic at Ocimum basilicum L. And O. Basilicum var. Purpurascens Benth., Observed with Open Source Software's PDF. Not. Bot. Horti Agrobo, 2016; 44: 4147. 